\title{
Determinants of Chronic Illness Among Aged Population in Ghana: A Multinomial Logit Approach*
}

\author{
${ }^{1}$ C. C. Nyarko, ${ }^{1}$ K. Agyarko, ${ }^{1}$ P. K. Nyarko and ${ }^{1}$ L. Brew \\ ${ }^{1}$ University of Mines and Technology, Box 237, Tarkwa, Ghana
}

Nyarko, C. C., Agyarko, K., Nyarko, P. K., Brew, L., (2021), "Determinants of Chronic Illness among Aged Population in Ghana: A Multinomial Logit Approach", Ghana Mining Journal, Vol. 21, No. 1, pp. 68-75.

\begin{abstract}
Generally, the constant change in demographic trends among the aged depict gradual increase in the size of the aged population globally. The aged population is often capitalised with degenerative conditions such as chronic illness which affect their ability to function effectively and often require special support. Despite the increase in the size of the aged population and their associated degenerative conditions, very few descriptive studies on the determinants of chronic illness among the aged has been researched especially in developing countries such as Ghana and there is no compelling evidence on the association of chronic illness and its determinants. Thus, this study seeks to analyse and predict the impact of age, gender, education, marital status, Quality of Life (QoL), social cohesion, settlement and depression on chronic illness among the aged population in Ghana. From the studies a Multinomial Logit Regression (MLR) was employed to analyse the data obtained from the Ghana Statistical Service (GSS) under, Ageing and Adult Health (SAGE), 2012. It was revealed that out of the 1384 sampled, $71 \%$ had no chronic illness whilst $22 \%$ and $7 \%$ had one and two or more chronic illness respectively. Again, it was observed that, Depression State, Gender, Marital Status and Settlement Type (rural or urban) play significant roles in determining the likelihood of the aged getting chronic illness while Physical Function, Social Cohesion, QoL, Age and Education Level were not statistically significant determinants of chronic illness. Our findings demonstrate that chronic illness among the aged is constantly increasing in Ghana especially in the urban communities and need to be addressed urgently through governmental policies and programs in the quest to help salvage the deteriorating conditions of the aged.
\end{abstract}

Keywords: Aged Population, Multinomial Logit Model, Chronic Illness

\section{Introduction}

Population ageing is increasingly becoming a significant issue globally leading to a dramatic increase in the numbers of people living into their seventies, eighties and nineties (Anon., 2005). According to World Health Organization (WHO) there are about 600 million people aged 60 years and above expected to double by the year 2025 with vast majority of them found in developing countries (Anon., 2005). The elderly population is usually, linked with degenerative conditions such as chronic illness which affect their ability to function effectively and often require special care and support (Bowling and Gabriel, 2007; Dugan and Lee 2013; Kpessa-White and Tsekpo, 2020). According to a report from Center for Disease Control (CDC) and Prevention, about $80 \%$ of Americans are living with at least one chronic disease and $50 \%$ of the elderly live with at least two chronic disease (Anon., 2003). The World Health Organization (WHO) in 2005 , reports chronic disease to be one of the leading causes of death in the world and estimated 35 million deaths among the aged population (Anon., 2005).

In Sub-Sahara Africa chronic illnesses among the elderly population put a lot of pressure on the youth because they are the major source of income and support for the elderly. Thus, the elderly in most developing countries like Sub-Sahara Africa are exposed to poverty, low coverage of health infrastructure and weak social welfare support institutions.

In Ghana, the elderly population is defined by the Ghana Statistical Service as persons who are 60 years or older. Ghana's population is relatively youthful, however, the constant change in demographic trends since the 1950s depict a gradual rise in the size of the elderly population (KpessaWhite, 2018). In 2010, the Population and Housing Census estimated the population of the aged in Ghana to have increased seven-and-half times from 1960 to 2010 namely from 213,477 and 1,643,381 respectively constituting 6.7 percent of the total national population in 2010 compared with 4.5 percent in 1960.

Chronic illnesses among the elderly in Ghana is notably associated with stroke, hypertension, diabetes and cancer which are among the top ten leading causes of death (Ayernor, 2012). Some of these factors operate on an individual level as a health behaviours or genetic factors which operate on a wider societal level. All these influencing factors are collectively known as determinants of health. Determinants that affect a person's health in a negative way are described as risk factors and they can increase the chances of developing chronic illness or interfere in the management of existing conditions. Chronic illness epidemic cannot be completely managed without understanding the socioeconomic determinants. Socioeconomic determinants such as education, income, social 
cohesion among others affect the quality of life of a person (Ng et al., 2010; Dale et al., 2013; Maresova et al., 2019).

Apart from the epidemiological evidence demonstrating the chronic disease burden and a few descriptive studies on the determinant of chronic illness, compelling evidence on the strength of association between some of these determinants and chronic illness has been lacking and very few of these researches have been done on the elderly population in Ghana. A study by Adoma and Yendaw (2014) used the descriptive statistics such as the mode and percentages to determine the most reported chronic disease among the aged in the Cape Coast Metropolitan Hospital in Ghana between 2004 and 2009. Whilst $\mathrm{Wu}$, et al. (2015) focused on the most reported chronic disease and found that hypertensive heart disease was the most reported case among selected Lower-Middle Income Countries including Ghana. Lidzén, 2008 and Lewis (2014), also investigated the role of private home cares in supporting the wellbeing of the aged and the role of family and the society in the care of the elderly respectively.

This paper therefore seeks to predict and determine the effects of chronic illness among the elderly population in Ghana.

\section{Resources and Methods Used}

\subsection{Data}

A secondary data was obtained from Ghana Statistical Service (GSS) under, Ageing and Adult Health (SAGE), 2012. The data was grouped into two main categories that is the dependent variable and the independent variables. The social, environmental, biomedical and demographic factors were considered as predictor variables (independent variables) and the Chronic illness as response variable. Chronic illness was categorised into 'No Chronic Illness (NCI)', 'One Chronic Illness (OCI)' and 'Two or more Chronic Illnesses (TCI)'.

Age was categorised into young old, middle old and oldest old. Educational level was grouped into "none to primary", "completed secondary/ high school" and "college or more". Depression State was also grouped under "none", "mild", "moderate" and "severe extreme". Settlements Type were also grouped under "rural" and "urban". Marital Status of the respondents was categorised as "never married", "currently married", "cohabiting", "divorced/separated", "widowed" and "others".

A Multinomial Logistic Regression (MLR) Model was used to analyse the relationship between the independent variables (determinants) and the dependent variables (chronic illness). Multinomial logistic regression was considered more appropriate because it does not assume normality, linearity, or homoscedasticity. It does have assumptions, such as the assumption of independence among the dependent variable choice. A Pearson Chi-Square test at 5\% level of significant was used to test the independence of the predictor variables. The specific hypothesis is:

$\mathrm{H}_{0}$ : Predictor variables are independent

$\mathrm{H}_{1}$ : Predictor variables are not independent

\subsection{Formulation of Multinomial Logit Model}

The study used Multinomial Logit Regression (MLR) because the data have more than two levels of categorical response variable (El-Habil, 2012). MLR model permits simultaneous comparison of more than one difference; that is, the log odds of three or more differences are estimated simultaneously (Garson, 2009). It also considers the effect of the covariates on categorical response. Thus, given a response variable $\mathrm{Y}$ with two measurement levels and explanatory variable $\mathbf{X}$, let

$$
\begin{aligned}
\Omega(x) & =p(Y=1 \mid X=x) \\
& =1-p(Y=0 \mid X=x)
\end{aligned}
$$

then, from Equation (1) we obtain Equation (2) as,

$$
\operatorname{logit}(\Omega(x))=\log \left(\frac{\Omega(x)}{1-\Omega(x)}\right)=\alpha+\beta x
$$

where the odds $=\left(\frac{\Omega(x)}{1-\Omega(x)}\right)$. This implies that the odds $=\exp (\alpha+\beta x)$

Thus, let $\mathrm{k}$ denotes the number of predictors for a binary response $\mathrm{Y}$. Then given the explanatory variables $x_{1}, x_{2}, \ldots, x_{k}$, the model for $\log$ odds is given by Equation (3).

$$
\operatorname{Logit}[P(Y=1)]=\alpha+\beta_{1} x_{1}+\beta_{2} x_{2}+\ldots+\beta_{k} x_{k}
$$

Hence, Equation (4)

$\Omega(x)=\frac{\exp \left(\alpha+\beta_{1} x_{1}+\beta_{2} x_{2}+\ldots+\beta_{k} x_{k}\right)}{1+\exp \left(\alpha+\beta_{1} x_{1}+\beta_{2} x_{2}+\ldots+\beta_{k} x_{k}\right)}$

The parameter $\beta_{i}$ refers to the effect of $x_{i}$ on the $\log$ odds that $Y=1$, controlling other $x_{j}, j \neq i$. For example, $\exp \left(\beta_{i}\right)$ is the multiplicative effect on the odds of a one unit increase in $x_{i}$ at a fixed level of other $x_{j}$ (El-Habil, 2012). If there are $n$ independent observations with q- explanatory variables and the qualitative response variable has $\mathrm{k}$ categories, then 
to construct the logits in the multinomial case, one of the categories must be considered the base level and all the logits are constructed relative to it. Any category can be used as the base level.

Thus, considering $\Omega_{j}$ as the multinomial probability of an observation falling in the $j^{\text {th }}$ category. Then the relationship between this probability and the q-explanatory variables, $x_{1}, x_{2}, \ldots, x_{q}$ is given by Equation (5):

$$
\log \left(\frac{\Omega_{j}\left(x_{i}\right)}{\Omega_{k}\left(x_{i}\right)}\right)=\alpha_{0}+\beta_{1 j} x_{1 i}+\beta_{2 j} x_{2 i}+\ldots+\beta_{q j} x_{q i}
$$

for $j=1, \ldots, k-1$ and $i=1, \ldots, n$. The model parameters are estimated by the method of Maximum Likelihood (Chatterjee and Hadi, 2006).

\section{Results and Discussion}

Table 1 presents the background characteristics of the respondents. The strength of the age category tends heavily towards 60 to 75 young old age category, while 76 to 85 middle old and 86 and above, oldest old category follows respectively with $20.2 \%$ of them being depressed, $11.9 \%$ had severe depression and majority not depressed. Most of the respondents belong to No education to Primary level category with college or more having the least number of respondents. $55.4 \%$ of the respondent were males. Seven out of 500 of the elderly reported to have never married with $0.4 \%$ of them still in marriage. Moreover, approximately $64 \%$ of them lived in the rural area.

Table 1 Distribution of Respondent by

\begin{tabular}{|c|c|c|}
\hline \multicolumn{3}{|c|}{ Background Characteristic } \\
\hline Variables & Frequency & Marginal \% \\
\hline $\begin{array}{l}\text { Age Categories } \\
60 \text { to } 75 \\
76 \text { to } 85 \\
86 \text { and above }\end{array}$ & $\begin{array}{l}948 \\
346 \\
88\end{array}$ & $\begin{array}{l}68.6 \% \\
25.0 \% \\
6.4 \%\end{array}$ \\
\hline $\begin{array}{l}\text { Depression State } \\
\text { None } \\
\text { Mild } \\
\text { Moderate } \\
\text { Severe }\end{array}$ & $\begin{array}{l}1103 \\
41 \\
74 \\
164\end{array}$ & $\begin{array}{l}79.8 \% \\
3.0 \% \\
5.4 \% \\
11.9 \%\end{array}$ \\
\hline $\begin{array}{l}\text { Education Level } \\
\text { None to Primary } \\
\text { Completed Secondary } \\
\text { College or above }\end{array}$ & $\begin{array}{l}1164 \\
175 \\
43\end{array}$ & $\begin{array}{l}84.2 \% \\
12.7 \% \\
3.1 \%\end{array}$ \\
\hline $\begin{array}{l}\text { Gender } \\
\text { Male } \\
\text { Female }\end{array}$ & $\begin{array}{l}766 \\
616\end{array}$ & $\begin{array}{l}55.4 \% \\
44.6 \%\end{array}$ \\
\hline $\begin{array}{l}\text { Marital Status } \\
\text { Never Married } \\
\text { Currently married } \\
\text { Cohabiting } \\
\text { Divorced } \\
\text { Widowed } \\
\text { Others }\end{array}$ & $\begin{array}{l}20 \\
695 \\
6 \\
194 \\
463 \\
4\end{array}$ & $\begin{array}{l}1.4 \% \\
50.3 \% \\
0.4 \% \\
14.1 \% \\
33.5 \% \\
0.3 \%\end{array}$ \\
\hline $\begin{array}{l}\text { Settlement Type } \\
\text { Urban } \\
\text { Rural }\end{array}$ & $\begin{array}{l}423 \\
959\end{array}$ & $\begin{array}{l}30.6 \% \\
69.4 \%\end{array}$ \\
\hline Valid & 1382 & $100 \%$ \\
\hline
\end{tabular}

Table 2 shows that $71.1 \%$ of the elderly population had No Chronic Illness (NCI), 22.1\% had One Chronic Illness (OCI) and the rest had at least Two Chronic Illness (TCI).

Table 2 Cases of Chronic Illness

\begin{tabular}{llll}
\hline \multicolumn{2}{l}{ Categories } & Frequency & Marginal\% \\
\hline \multirow{3}{*}{ Chronic } & NCI & 983 & $71.1 \%$ \\
illness & TCI & 305 & $22.1 \%$ \\
\hline
\end{tabular}

\subsection{Model Fitting}

The first step considered was to check for independence of the proposed determinant of chronic illness. The results in Table 3 indicate that the observed data are independent with p-value of 0.12 which is greater than the $5 \%$ level of significance. Thus, there is not enough evidence to reject the null hypothesis. This also indicates that the observed data is well fitted by the model.

Table 3 Goodness-of-Fit

\begin{tabular}{llll}
\hline & Chi-Square & Df & Sig. \\
\hline Pearson & 2775.69 & 2688 & 0.12 \\
Deviance & 1951.90 & 2688 & 1.00 \\
\hline
\end{tabular}

\subsection{Evaluation of the Usefulness of the MLR Model}

The accuracy classification of the model was computed using the marginal percentages of 'No Chronic Illness (NCI)', 'One Chronic Illness (OCI)' and 'Two or More Chronic Illness (TCI)' as shown in Table 2 . The proportion by chance accuracy rating was $55.9 \%\left(0.711^{2}+0.221^{2}+0.068^{2}=0.559\right)$. According to Monyail et al. (2016), the standard that shows the usefulness of MLR model should be $25 \%$ improvement over the rate of accuracy achievable by chance. Thus, the classification accuracy rate should be at least $69.9 \%$ for the MLR model to be adequate. Table 4 shows the comparison of the observed and predicted state of chronic illness and the extent to which they can be correctly predicted by the model. The correctly classified cases are on the diagonal in Table 4 . The overall correct classification for all cases is $70.4 \%$ and it is greater than the proportion by chance accuracy criteria of 69.9. This indicates that the model improves on the proportion by chance accuracy rate of at least $25 \%$ and therefore the criterion for classification accuracy is satisfied and the model is adequate.

Table 4 Classification Accuracy

\begin{tabular}{lcccc}
\hline & \multicolumn{4}{c}{ Predicted } \\
\cline { 2 - 5 } Observed & NCI & OCI & TCI & \% Correct \\
\hline NCI & $\mathbf{9 6 0}$ & 14 & 9 & 97.7 \\
OCI & 291 & $\mathbf{9}$ & 5 & 3.0 \\
TCI & 85 & 5 & $\mathbf{4}$ & 4.3 \\
Overall \% & 96.7 & 2.0 & 1.3 & 70.4 \\
\hline
\end{tabular}




\subsubsection{Likelihood Ratio Tests (LRT)}

The Likelihood Ratio Tests shows the overall relationship between an independent variable and dependent variable while the Wald test determines whether or not the independent variable is statistically significant in differentiating between any two groups of the dependent variable. From Table 5, the chi-squared value for social cohesion is 4.553 with a p-value of 0.103 which is greater than the significant level, alpha ( $\alpha=0.05$ ) indicating there is no strong evidence that Social Cohesion has a relationship with chronic illness likewise, Physical Function and Age.

However, Quality of Life (QoL), Educational Level, Depression State, Gender, Marital Status and Type of Settlement all have p-values less than 0.05 which indicates that there is strong evidence of their relationship with chronic illness. Though the LRT shows that some of the determinant considered have strong association with chronic illness it does not necessary mean that these factors are statistically significant in distinguishing the state of chronic illness. The Wald test was used to make such distinction.

Table 5 Likelihood Ratio Test

\begin{tabular}{lcccc}
\hline & MFC & \multicolumn{3}{c}{ LRT } \\
\cline { 2 - 5 } $\begin{array}{l}\text {-2Log } \\
\text { Likelihood of } \\
\text { Reduced Model }\end{array}$ & $\begin{array}{c}\text { Chi- } \\
\text { Square }\end{array}$ & Df & Sig. \\
\hline $\begin{array}{l}\text { Effect } \\
\begin{array}{l}\text { Social } \\
\text { Cohesion }\end{array}\end{array}$ & 1953.28 & 0.00 & 0 & $\cdot$ \\
$\begin{array}{l}\text { Physical } \\
\text { Function }\end{array}$ & 1957.84 & 4.55 & 2 & 0.10 \\
$\begin{array}{l}\text { Quality of } \\
\text { Life }\end{array}$ & 1959.81 & 6.19 & 2 & 0.14 \\
$\begin{array}{l}\text { Age } \\
\text { Categories }\end{array}$ & 1954.14 & 0.86 & 2 & 0.04 \\
$\begin{array}{l}\text { Education } \\
\text { Level }\end{array}$ & 1974.16 & 20.88 & 4 & 0.00 \\
$\begin{array}{l}\text { Depression } \\
\text { State }\end{array}$ & 2009.34 & 56.06 & 6 & 0.00 \\
$\begin{array}{l}\text { Gender } \\
\text { Type of }\end{array}$ & 1963.60 & 10.32 & 2 & 0.01 \\
$\begin{array}{l}\text { Settlement } \\
\text { Marital Status }\end{array}$ & 1960.64 & 7.36 & 2 & 0.03 \\
\hline
\end{tabular}

\subsection{Parameter Estimation of the Determinants}

The results for fitting the MLR models to the determinant of chronic illness are presented in Table 6 and Table 7. They show the coefficient estimate (B), the standard errors (S. E), the Wald Statistic, the odds ratio (OR) represented by $\operatorname{Exp}(\mathrm{B})$ and their corresponding $95 \%$ confidence intervals for each state of chronic illness. In order to test for the significance of each determinant, the Wald Statistic together with the Significance value (Sig) was used. For this study, we tested if the determinant of chronic illness in the elderly population can significantly distinguish the state of chronic illness among the aged against the reference state which is Two or more Chronic Illness (TCI).

Those determinants with significant values greater than 0.05 implies that statistically there is not enough evidence to show that they can distinguish between each state of chronic illness and the reference variable 'TCI'. Thus, they cannot be regarded as significant contributors. From Table 6 Social Cohesion, QoL, Age Category, Education Level and Physical Function are unable to distinguish between NCI and TCI, and therefore cannot be used as a strong determinant of chronic illness. Furthermore, Depression State, Gender, Marital Status and Settlement Type were significant in the model. This agrees with the results of the studies by $\mathrm{Wu}$ et al. (2015) on some common determinants of chronic non-communicable diseases among older adults in several countries including Ghana. They found that hypertension prevalence was higher in folks living in the urban communities than those living in the rural communities. This implies that the type of settlement plays a significant role in older folks with chronic diseases as seen in this study. Moreover, Ayernor (2012) also studied diseases of ageing in Ghana. He also noticed that the type of settlement also is key to some chronic diseases that affect the aged in Ghana. This implies that indeed settlement type is a significant contributor to chronic diseases among the aged in Ghana.

\subsection{Prediction of Chronic Illness}

\subsubsection{Odds Ratio of Model Development for NCI}

Odds are the probability of an event occurring divided by the probability of the event not occurring. An odds ratio is the odds of the event in one group, thus those exposed to chronic illness, divided by the odds in another group not exposed to chronic illness. Odds are simply a different expression of the probability: the probability of an event divided by the probability of the event not happening, thus, the odds of no chronic illness would be (probability of no chronic illness)/ (1-probability of no chronic illness).

\subsubsection{Prediction of Chronic Illness for NCI}

The final significant model for chronic illness when NCI was compared to TCI is as shown in Equation (6): 
$\operatorname{logit}(p)=12.98+1.92 b+1.05 c+0.95 d-12.03 e-11.75 f-$

$12.28 g-12.34 h-12.1 i-0.63 j$

where ' ' $b$ ' and ' $c$ ' represents Depression State (none and moderate respectively) of the respondents. Also, ' $\mathrm{d}$ ' is male respondent of the Gender category. From 'e 'through to ' $\mathrm{i}$ ' of the model indicates the Marital Status of the respondents and ' $\mathrm{j}$ ' is urban respondents. The $\operatorname{logit}(p)$ in Equation (6) is the $\log$ odds of the elderly population with NCI.

3.4.3 Prediction of Chronic Illness for One Chronic Illness (OCI)

The final significant model for chronic illness when one chronic illness category was compared to two or more chronic illness is as shown in Equation (7); $\operatorname{logit}(p)=12.90+0.96 b+0.68 d-12.87 e$

$-12.76 f-13.74 g-13.33 h-13.04 i-0.45 j$

where ' $b$ ' to ' $j$ ' remain same as defined in Equation (6) and logit $p$ in Equation (7) is the log odds of the elderly population with OCI.

\subsection{Numerical Error Checks}

The standard errors of the coefficient estimate in Table 6 and Table 7 are used to check for numerical errors or multicollinearity in the MLR solution. Standard errors that are greater than 2.0 indicate numerical problems such as multicollinearity (Monyail et al., 2016) among the independent factors that are considered to affect chronic illness. From Table 6 and Table 7, all the standard errors are less than 2.0. This indicates that there is no multicollinearity among the determinants considered.

Table 6 Parameter Estimation for NCI

\begin{tabular}{|c|c|c|c|c|c|c|c|c|}
\hline \multirow{2}{*}{$\begin{array}{l}\text { No Chronic Illness } \\
\quad(\mathrm{NCI})\end{array}$} & \multirow[t]{2}{*}{ B } & \multirow[t]{2}{*}{ S. E } & \multirow[t]{2}{*}{ Wald } & \multirow[t]{2}{*}{ df } & \multirow[t]{2}{*}{ Sig } & \multirow[t]{2}{*}{$\operatorname{Exp}(B)$} & \multicolumn{2}{|c|}{$\begin{array}{c}\text { 95\% Confidence Interva } \\
\text { for } \operatorname{Exp}(B)\end{array}$} \\
\hline & & & & & & & $\begin{array}{l}\text { Lower } \\
\text { Bound }\end{array}$ & $\begin{array}{l}\text { Upper } \\
\text { bound }\end{array}$ \\
\hline \multicolumn{9}{|l|}{ Parameters } \\
\hline Intercept & 12.98 & 1.69 & 59.20 & 1 & 0.00 & & & \\
\hline Social Cohesion & -0.29 & 0.17 & 2.89 & 1 & 0.09 & 0.75 & 0.54 & 1.05 \\
\hline Physical Function & -0.41 & 0.21 & 3.92 & 1 & 0.05 & 0.67 & 0.45 & 0.10 \\
\hline Quality of Life & 0.31 & 0.22 & 1.96 & 1 & 0.16 & 1.36 & 0.88 & 2.12 \\
\hline \multicolumn{9}{|l|}{ Age Categories } \\
\hline 60 to 75 & 0.25 & 0.46 & 0.28 & 1 & 0.57 & 1.28 & 0.52 & 3.17 \\
\hline 76 to 85 & 0.27 & 0.47 & 0.33 & 1 & 0.57 & 1.31 & 0.52 & 3.31 \\
\hline 86 and above & 0.00 & & & 0 & & & & \\
\hline \multicolumn{9}{|l|}{ Depression State } \\
\hline None & 1.92 & 0.28 & 45.85 & 1 & 0.00 & 6.83 & 3.92 & 11.91 \\
\hline Mild & 1.09 & 0.67 & 2.68 & 1 & 0.10 & 2.98 & 0.81 & 10.99 \\
\hline Moderate & 1.05 & 0.48 & 4.81 & 1 & 0.03 & 2.85 & 1.12 & 7.28 \\
\hline Severe & 0.00 & & & 0 & & & & \\
\hline \multicolumn{9}{|l|}{ Education Level } \\
\hline None to Primary & 0.22 & 0.79 & 0.08 & 1 & 0.78 & 1.25 & 0.27 & 5.81 \\
\hline Secondary & -1.02 & 0.80 & 1.60 & 1 & 0.21 & 0.36 & 0.08 & 1.75 \\
\hline College/above & 0.00 & & & 0 & & & & \\
\hline \multicolumn{9}{|l|}{ Gender } \\
\hline Male & 0.95 & 0.32 & 8.84 & 1 & 0.00 & 2.59 & 1.38 & 4.86 \\
\hline Female & 0.00 & & & 0 & & & & \\
\hline \multicolumn{9}{|l|}{ Marital Status } \\
\hline Never Married & -12.03 & 1.52 & 62.79 & 1 & 0.00 & 0.00 & 0.00 & 0.00 \\
\hline Currently Married & -11.75 & 1.10 & 113.87 & 1 & 0.00 & 0.00 & 0.00 & 0.00 \\
\hline Cohabiting & -12.28 & 1.63 & 57.12 & 1 & 0.00 & 0.00 & 0.00 & 0.00 \\
\hline Divorced & -12.34 & 1.10 & 125.42 & 1 & 0.00 & 0.00 & 0.00 & 0.00 \\
\hline Widowed & -12.10 & 1.06 & 130.80 & 1 & 0.00 & 0.00 & 0.00 & 0.00 \\
\hline Others & 0.00 & & & 0 & & & & \\
\hline \multicolumn{9}{|l|}{ Settlement Type } \\
\hline Urban & -0.63 & 0.238 & 7.00 & 1 & 0.01 & 0.53 & 0.34 & 0.85 \\
\hline Rural & 0.00 & & & 0 & & & & \\
\hline
\end{tabular}




\begin{tabular}{|c|c|c|c|c|c|c|c|c|}
\hline \multirow{2}{*}{$\begin{array}{l}\text { No Chronic Illness } \\
\quad(\mathrm{NCI})\end{array}$} & \multirow[t]{2}{*}{ B } & \multirow[t]{2}{*}{ S. E } & \multirow[t]{2}{*}{ Wald } & \multirow[t]{2}{*}{$\mathrm{df}$} & \multirow[t]{2}{*}{ Sig } & \multirow[t]{2}{*}{$\operatorname{Exp}(B)$} & \multicolumn{2}{|c|}{$\begin{array}{l}\text { 95\% Confidence Interval } \\
\text { for } \operatorname{Exp}(\mathrm{B})\end{array}$} \\
\hline & & & & & & & $\begin{array}{l}\text { Lower } \\
\text { Bound }\end{array}$ & $\begin{array}{l}\text { Upper } \\
\text { bound }\end{array}$ \\
\hline \multicolumn{9}{|l|}{ Parameters } \\
\hline Intercept & 12.90 & 1.40 & 85.32 & 1 & 0.00 & & & \\
\hline Social Cohesion & -0.14 & 0.18 & 0.62 & 1 & 0.43 & 0.87 & 0.61 & 1.23 \\
\hline Physical Function & -0.33 & 0.22 & 2.27 & 1 & 0.13 & 0.72 & 0.47 & 1.11 \\
\hline Quality of Life & 0.55 & 0.24 & 5.39 & 1 & 0.22 & 1.73 & 1.09 & 2.75 \\
\hline \multicolumn{9}{|l|}{ Age Categories } \\
\hline 60 to 75 & 0.41 & 0.50 & 0.67 & 1 & 0.41 & 1.50 & 0.56 & \\
\hline $\begin{array}{l}76 \text { to } 85 \\
86 \text { and above }\end{array}$ & $\begin{array}{l}0.36 \\
0.00\end{array}$ & 0.51 & 0.50 & $\begin{array}{l}1 \\
0\end{array}$ & 0.48 & 1.43 & 0.53 & 3.89 \\
\hline Depression State & & & & & & & & \\
\hline None & 0.96 & 0.30 & 10.32 & 1 & 0.00 & 2.61 & 1.45 & 4.67 \\
\hline Mild & 0.46 & 0.72 & 0.42 & 1 & 0.52 & 1.59 & 0.39 & 6.45 \\
\hline Moderate & 0.57 & 0.51 & 1.24 & 1 & 0.27 & 1.76 & 0.65 & 4.78 \\
\hline $\begin{array}{l}\text { Moderate } \\
\text { Severe }\end{array}$ & 0.00 & & & 0 & & & & \\
\hline \multicolumn{9}{|l|}{ Education Level } \\
\hline None to Primary & 0.22 & 0.79 & 0.08 & 1 & 0.78 & 1.25 & 0.27 & 5.81 \\
\hline Secondary & -1.02 & 0.80 & 1.60 & 1 & 0.21 & 0.36 & 0.08 & 1.75 \\
\hline College/above & 0.00 & & & 0 & & & & \\
\hline \multicolumn{9}{|l|}{ Gender } \\
\hline Male & 0.68 & 0.34 & 3.95 & 1 & 0.04 & 1.97 & 1.01 & 3.83 \\
\hline Female & 0.00 & & & 0 & & & & \\
\hline \multicolumn{9}{|l|}{ Marital Status } \\
\hline Never Married & -12.87 & 1.14 & 127.16 & 1 & 0.00 & 0.00 & 0.00 & 0.00 \\
\hline Currently Married & -12.76 & 0.35 & 1316.28 & 1 & 0.00 & 0.00 & 0.00 & 0.00 \\
\hline Cohabiting & -13.74 & 1.49 & 85.69 & 1 & 0.00 & 0.00 & 0.00 & 0.00 \\
\hline Divorced & -13.33 & 0.35 & 1422.90 & 1 & 0.00 & 0.00 & 0.00 & 0.00 \\
\hline Widowed & -13.04 & 0.00 & & 1 & 0.00 & 0.00 & 0.00 & 0.00 \\
\hline Others & 0.000 & & & 0 & & & & \\
\hline \multicolumn{9}{|l|}{ Settlement Type } \\
\hline Urban & -0.45 & 0.25 & 3.15 & 1 & 0.03 & 0.637 & 0.387 & 1.05 \\
\hline Rural & 0.000 & 0.20 & 5.10 & 0 & $0.0 \mathrm{~J}$ & 1 & 0.001 & $1.0 \mathrm{~J}$ \\
\hline
\end{tabular}

\section{Conclusions}

The MLR model was used to analyse the relation between chronic illness among the aged population and its determinants. The determinants considered were, Age, Gender, Education, Marital Status, Quality of Life, Social Cohesion, Settlement Type (rural or urban) and Depression State. It was revealed that out of the 1384 sampled, $71 \%$ had no chronic illness whilst $22 \%$ and $7 \%$ had one and two or more chronic illness respectively. Again, it was revealed that, Depression State, Gender, Marital Status and Settlement Type (rural or urban) play a significant role in determining the likelihood of the aged population getting chronic illness while Physical Function Social Cohesion, QoL, Age and Education Level were not significant determinants of chronic illness. Our findings further indicate that the likelihood of chronic illness among the aged is constantly increasing in Ghana especially in the urban communities. This need to be addressed through governmental policies and educational programs on ageing to improve their health issues and livelihood. The paper concludes that government should consider coverage for chronic illness with regards to the aged under the National Health Insurance Scheme (NHIS) to help curb the rate of death among the elderly in Ghana.

\section{References}

Adom, P. O. and Yendaw, E. (2014), “Ageing and Chronic Diseases in Ghana: A Case Study of Cape Coast Metropolitan Hospital", International Journal of Nursing, Vol. 1, No. 1, pp. 25-36.

Alamian, A., and Paradis, G. (2012), "Individual and Social Determinants of Multiple Chronic Disease Behavioral Risk Factors Among Youth", BMC Public Health, Vol. 12, pp. 224 -230.

Anon. (2003), "From the Centers for Disease Control and Prevention. Public Health and Aging: Trends in Aging-United States and 
Worldwide", the Journal of the American Medical Association, $1373 \mathrm{pp}$.

Anon. (2005), "Preventing chronic diseases: a vital investment", WHO Global Report. Technical report, $13 \mathrm{pp}$.

Ayernor, P. K. (2012), "Diseases of Ageing in Ghana", Ghana Medical Journal, Vol.46, No. 2 pp. 18-22.

Bayaga, A. (2010), "Multinomial Logistic Regression: Usage and Application in Risk Analysis", Journal of Applied Quantitative Methods, Vol. 5, No. 2, pp. 288-297.

Bowling, A. and Gabriel, Z. (2007), "Lay Theories of Quality of Life in Older Age", Ageing and Society, 848 pp.

Chatterjee, S. and Hadi, A. (2006), "Regression Analysis by Example", John Wiley and Sons, $352 \mathrm{pp}$.

Dale, C. E., Bowling, A., Adamson, J., Kuper, H., Amuzu, A., Ebrahim, S., Casas, J. P. and Nuesch, E. (2013), "Predictors of Patterns of Change in Health-Related Quality of Life in Older Women Over Seventy Years: Evidence from a Prospective Cohort Study", Age Ageing, Vol. 4, No. 2, pp. 312-318.

Dugan, E. and Lee, C. M. (2013), "Biopsychosocial Risk Factors for Driving Cessation: Findings from the Health and Retirement Study". Journal of Aging and Health, Vol 25 No. 8, pp. 13131328.

El-Habil, A. M. (2012), "An Application on Multinomial Logistic Regression Model", Pak.J.Stat.Oper.Res., Vol. 8, No. 2, pp. 271-291.

Garson, D. (2009), "Logistic Regression with SPSS ”. North Carolina State University, Public Administration Program, 10 pp.

Kpessa-Whyte, M. (2018), “Ageing and Demographic Transition in Ghana: State of the Elderly and Emerging Issues", The Gerontologist, Vol. 58, No. 3, pp. 403-408.

Kpessa-Whyte, M. and Tsekpo, K. (2020), "Lived Experiences of the Elderly in Ghana: Analysis of Ageing Policies and Options for Reform", Journal of Cross-Cultural Gerontology, pp. 112.

Lidzén, L. (2008), “A Comparative Study of the Social Welfare Provided by Three Christian Churches in Accra”, Institutionen för humaniora och samhällsvetenskap, University College of Gävle, 24 pp.

Maresova, P., Javanmardi, E., Barakovic, S., Husic, J. B., Tomsone, S., Krejcar, O. and Kuca, K. (2019), "Consequences of Chronic Diseases and Other Limitations Associated with Old Age - A Scoping Review", BMC Public Health, Vol.19, No. 1431, pp. 1-17.

Monyail, S., Lesaoana, M., Darikwa, T. and Nyamugure, P. (2016), "Application of Multinomial Logistic Regression to Educational Factors of the 2009 General Household Survey in South Africa", Journal of Applied Statistics, Vol. 43, No. 1, pp. 128-139.

Ng, N., Kowal, P., Kahn, K., Naidoo, N. and Abdullah, S. (2010), "Health Inequalities Among Older Men and Women in Africa and Asia: Evidence from Eight Health and Demographic Surveillance System Sites in the INDEPTH WHO-SAGE Study", Glob Health Action, Vol. 3, pp. 1-16.

Okediji, P. T., Ojo, O. A., Ojo, I. A., Ojo, E,. O. and Abioye-Kuteyi, A. E. (2017), "The Economic Impacts of Chronic Illness on Households of Patients in Ile-Ife, South-Western Nigeria", Cureus, Vol. 9, No. 10, pp. 1-23.

Wu, F., Guo, Y., Chatterji, S., Zheng, Y., Naidoo, N., Jiang, Y. Biritwum, A. Y., Minicuci, N., Salinas-Rodriquez, A., Manrque-Espinoza B., Maximova, T., Peltzer, K., Phaswanamafuya, N., Snodgrass, J. J., Thiele, E., Ng, N. and Kowal, P. (2015), "Common Risk Factors for Chronic Non-Communicable Diseases Among Older Adults in China, Ghana, Mexico, India, Russia and South Africa”, BMC Public Health, Vol. 15, No. 88 , pp. $1-13$.

\section{Authors}

C. C. Nyarko is a Senior Lecturer at the Mathematical Sciences Department of the University of Mines and Technology (UMaT) Tarkwa Ghana. She holds a PhD in Mathematics, MPhil in Statistics from University of Mines and Technology and University of Ghana, respectively. She was awarded a BSc. Ed degree in Mathematics at Obafemi Awolowo University, Adeyemi Campus Ondo, Nigeria. She is a member of the Ghana Statistical Association, Ghana Mathematics Society and International Biometric Society of Ghana. Her research interests include, Applied Statistics (Binomial Logistic Regression, Multinomial logit Analysis, Probability Distribution Theory), Mathematical and Epidemiological Modelling.

K. Agyarko is a Lecturer at the Mathematical Sciences Department of University of Mines and Technology (UMaT). He holds MPhil in Actuarial Science, from Kwame Nkrumah University of Science and Technology (KNUST), Kumasi and BSc (Hons) in Mathematics from University of Mines and Technology (UMaT), Tarkwa. He is a member of the Actuarial Society of Ghana and an Associate Member of the Institute of Mathematics and its Application (IMA), UK. His research interests are in the areas of Insurance Claims, Stochastic Processes, Bayesian Statistics and Probability theory.

P. K. Nyarko is a Senior Lecturer at the Department of Mathematical Sciences in UMaT. He holds a PhD in Mathematics from the University of Mines and Technology (UMaT), MSc in Mathematics from the Kwame Nkrumah University of Science and Technology, and a BSc in Mathematics from the University of Cape Coast, all in Ghana. He is a member of Ghana Mathematics Society as well as the Mathematical Association of Ghana. His research areas include 
dynamical systems and mathematical applications to forest dynamics.

L. Brew is a Senior Lecturer at the Department of Mathematical Sciences at the University of Mines and Technology, (UMaT) Tarkwa. He holds PhD in Mathematics from UMaT and MSc in Mathematics from Kwame Nkrumah University of Science and Technology (KNUST), Kumasi, Ghana. His research areas include Algebraic topology, Statistics, Time Series Analysis and Abstract Algebra. 